\title{
Ekotehokas pihatto - rakennusmateriaalivertailu MIPS-menetelmällä
}

\author{
Tapani Kivinen ${ }^{1)}$ ja Petro Tamminen ${ }^{2)}$ \\ ${ }^{1)}$ MTT Kotieläintuotannon tutkimus, Vakolantie 55,03400Vihti, tapani.kivinen@mtt.fi \\ ${ }^{2)}$ Helsingin Yliopisto, Agroteknologian laitos, Koetilantie 3,Viikki, petro.tamminen@helsinki.fi
}

\section{Tiivistelmä}

MIPS (Material Input Per Service Unit) on ekotehokkuuden indikaattori. OECD on määritellyt sen seuraavasti: "Ekotehokkuus on tuotteiden ja palvelujen arvo jaettuna ympäristöön kohdistuvien paineiden summalla". MIPS mittaa materiaalivirtoja ja jakaa ne palvelusuoritteella. Materiaalien mittari on MI, joka saadaan laskettua Wuppertal-Instituutin julkaisemien MI-kerrointen. Kulutettu materiaalimäärä ilmoitetaan neljässä eri kategoriassa uusiutumattomana ja uusiutuvana materiaalikulutuksena sekä veden ja ilman kulutuksena. Menetelmä keskittyy rakennusmateriaalien hankinnan ja valmistamisen sekä itse rakennusvaiheen materiaalivirtojen selvittämiseen. Näin ollen käytönaikaisia tai purkamisen aiheuttamia materiaalivirtoja ei tarkastella.

Materiaalitehokkuuden laskentakohteeksi valittiin pohjaratkaisultaan $2+2$-rivinen 146 parsipaikkainen kahden lypsyrobotin pihatto. Rakennus edustaa kokoluokaltaan sitä pihattomallia, jota tulevaisuudessa tullaan maassamme rakentamaan. Rakennuksen leveys on $27 \mathrm{~m}$ ja pituus $72 \mathrm{~m}$, kerrosalaa yhteensä $2130 \mathrm{~m}^{2}$. Rakennuksen tilavuus on $6100 \mathrm{~m}^{3}$.

Rakennusten sisustus eli lypsy- ja rehujärjestelmät, lannanpoiston koneet ja parsikalusteet oletettiin kaikissa vaihtoehdoissa samoiksi, joten niiden MIPS-vaikutukset olisivat olleet samoja. Tästä syystä sisustusrakenteet rajattiin tarkastelun ulkopuolelle. Lasketuissa malleissa tarkasteltiin pelkästään rakennuksen vaippaa, seiniä, kattoa ja lattiaa. Runkovaihtoehtoja oli kaikkiaan 7 , joiden voidaan kattavan kaikki sellaiset runkotekniikat, mitä Suomessa voidaan ajatella rakennettavan. Perustapauksena pidettiin maassamme yleisesti rakennettavaa eristettyä betonielementtiseinärunkoa. Toinen versio oli täysbetonielementtipihatto, kolmas teräksinen kolminivelkehäpihatto, neljäs tiheä puupilari-palkkiratkaisu, viides harva puupilari-palkkiratkaisu, kuudes naulalevyristikkokatto ja seitsemäs liimapuinen kolminivelkehärakenne

Rakennusten kokonaismateriaalivirrat laskettiin taulukkolaskentaohjelmaan pohjautuvalla työkalulla. Mukaan otettiin eri lähteistä myös hiilidioksidikertoimet, raaka-ainemenekki, tuotannossa syntyneen jätteen määrä sekä käytetty energia jaettuna uusiutuvaan ja uusiutumattomaan energiaan. MIPStermin mukaisesti materiaalikulutus laskettiin parsipaikkaa kohden. Eri runkovaihtoehdoissa materiaalikulutus oli pienimmillään noin 30 tonnia ja enimmillään 37,5 tonnia parsipaikkaa kohden. Ekotehokas rakentamistapa käyttää mahdollisimman paljon uusiutuvia luonnonvaroja, mikä suosii puuraaka-aineeseen perustuvia ratkaisuja. Samasta syystä betoniratkaisut ovat ekotehokkuuden kannalta epäsuotuisampia. Energian kokonaistarve tarkastelluissa runkovaihtoehdoissa oli pienimmillään 7700 megaloujea ja enimmillään liki 14000 megajoulea parsipaikkaa kohden. Ekotehokas rakentamistapa käyttää mahdollisimman paljon uusiutuvaa energiaa, mikä suosii materiaali-intensiteetin tapaan puuraakaaineeseen perustuvia ratkaisuja. Aivan samasta syystä betoniratkaisut ovat energiatehokkuuden kannalta epäsuotuisampia.

Hiilidioksidipäästöt kuvaavat rakennusmateriaalien tuotantovaiheessa ja rakennusvaiheessa syntyviä päästöjä. Päästötarkastelussa puu- ja betoniratkaisut käyttäytyvät samalla trendillä kuin materiaali-intensiteetin, energian ja jätteiden muodostuksen tapauksissa: puuratkaisut ovat ympäristöystävällisempiä kuin betoniratkaisut. Kiintoisaa on se, että materiaali- ja energiaintensiteetissä hyvin pärjännyt teräsrunkomalli muuttui hiilidioksidipäästöissä epäedullisemmaksi.

Tarkasteltujen neljän muuttujan - materiaali-intensiteetti, energian kulutus, jätteiden määrä ja CO2-päästöt - yhteisvaikutuksena voidaan todeta, että vähiten ympäristöä rasittavat rakennuskonseptit ovat liimapuinen kolminivelkehä ja puupilari-palkkirunko ilman eristeitä eli kylmäpihattona. Kun kylmäpihattojen rakennus- ja liitostekniikka mietitään jo uudisrakennusvaiheessa modulaariseksi, päästään helposti korjattaviin ja purettaviin rakennustyyppeihin, joiden osia voidaan purkuvaiheenkin jälkeen valikoidusti käyttää seuraavissa uudisrakennuksissa. Näin ekotehokkuutta voidaan kasvattaa entisestään. 




Kuva 1. laskentakohteena ollut $2130 \mathrm{~m}^{2}$ pihatto (lähde: DeLaval ja RSV-insinöörityö Oy), pihaton leveys oli $27 \mathrm{~m}$, pituus $72 \mathrm{~m}$ ja tilavuus $6100 \mathrm{~m} 3$.

Perustapauksena pidettiin maassamme yleisesti rakennettavaa eristettyä betonielementtiseinärunkoa, jossa vesikaton kantavat liimapuupalkit tukeutuvat keskialueen teräspilareihin. Vesikattona on eristetty termisol -elementti ja vesikatteena pelti. Tästä mallista laskettiin vain lämpöeristetty versio.
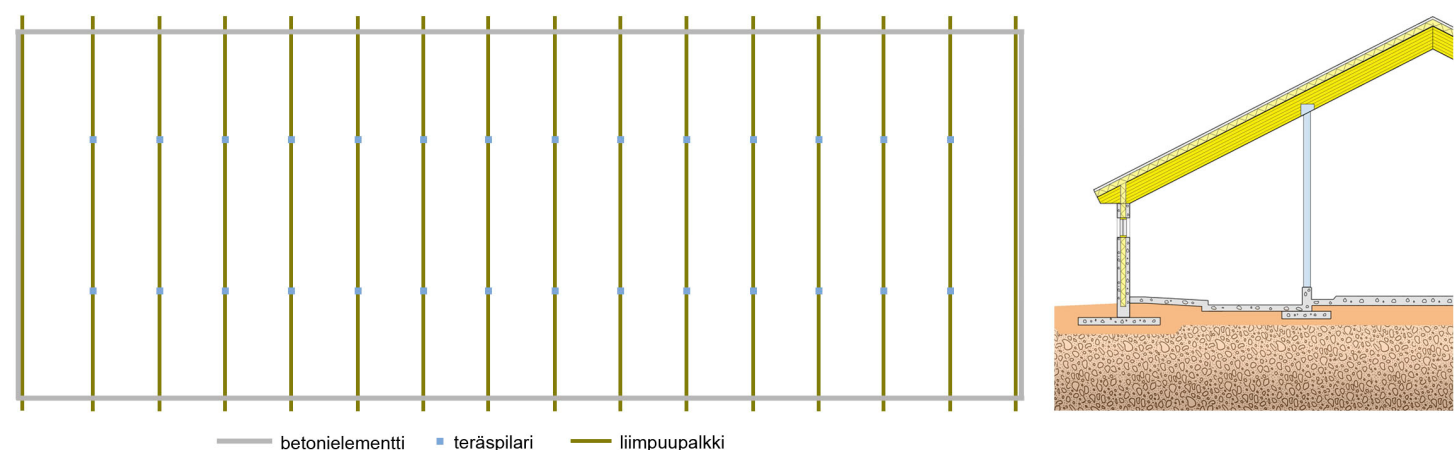

Kuva 2. Peruspihatto, jossa lämpöeristetty betonielementtiseinä, teräspilarit, liimapuupalkit ja termisol-katto. Pohjakuvassa on esitetty vesikaton kantavat pakit ja pilarien sijainti, leikkauskuva tarkentaa rakennetekniikkaa.

Täysbetonielementtipihatto on betoniteollisuuden kehittämä malli, jossa perinteisen eristetyn betonisandwich seinäelementin lisäksi keskialueen pilarit ja palkit ovat betonia, jotka edelleen kantavat betonisia TT-laattoja. Laattojen päälle tulee tiivis villa ja yksikerroskate. Tästä mallista laskettiin vain lämpöeristetty versio.


- betonielementti - betonipilari $=$ betonipalkki || $\mid$ betoniset TT-kattolaatat

Kuva 3. Täysbetonielementtipihatto, jossa lämpöeristetty betonielementtiseinä, betonipilarit- ja palkit, TT-betonilaata, eriste ja vesikate. 
Teräksinen kolminivelkehäpihatto on konsepti, jota esiintyy Keski-Euroopassa, Tanskassa ja osin EteläRuotsissa, mutta on vielä harvinainen Suomessa. Toisiokannattajina on sahatavaralankkuja ja vesikatteena kuitusementtiaaltolevy. Seinät ovat avoimet verhoseinällä tai pelkillä tuuliverkoilla varustetut. Tästä mallista laskettiin vain kylmäpihattoversio.


Kuva 4. Eristämätön eli kylmä teräksinen kolminivelkehärakenne.

Tiheä puupilari-palkkiratkaisu perustuu omasta metsästä otettuun kuorittuun pyöreään tukkiin, josta on tehty palkit ja kyllästetyt pilarit. Pilarit toimivat rakenteellisesti mastoina ja ne upotetaan maahan $2 \mathrm{~m}$ syvyyteen, jolloin paalutuksia ei tarvita Toisiokannattajat ovat sahatavaraa, mikä sanelee sekä palkkien dimensiot että pilareiden lukumäärän, jotka sijaitsevat $4 \times 4 \mathrm{~m}$ tai korkeintaan $4 \times 6$ m moduuliruudukossa. Tästä mallista laskettiin kylmäpihattoversio sekä lämpöeristetty versio.


Kuva 5. Tiheä puupilari-palkkirakenne, pilareita yhteensä $120 \mathrm{kpl}$.

Harva puupilari-palkkiratkaisu perustuu oman metsän tuotteisiin, kuten edellinenkin versio. Poikkeuksena tekevät vesikaton pääkannattajat, jotka ovat joko kerto- tai liimapuuta. Toisiokannattajat voivat olla järeätä sahatavaraa tai kertopuuta. Näin pilareita on harvemmassa ja sijaitsevat 4,8 x 8-10 m ruudukossa. Pilareiden lukumäärä on 64 kpl. Tästä mallista laskettiin kylmäpihattoversio sekä lämpöeristetty versio.


Kuva 6. Harva puupilari-palkkirakenne, pilareita $64 \mathrm{kpl}$. 
Naulalevyristikkokatto edustaa rakennustapaa, joka Suomessa on väistynyt järeämpien liimapuupalkkiratkaisujen tieltä. Tämä malli on yleisesti käytetty $\mathrm{mm}$. Kanadassa ja on täysin käyttökelpoinen Suomessakin erityisesti puoliavoimissa viileissä ja eristämättömissä kylmäpihatoissa. Ulkoseinillä kantavana runkona on puuranka, keskialueella teräspilari ja -palkki. Näihin tuetaan naulalevyristikot ja lämpöeriste asennetaan alapaarteen tasolle. Tästä mallista laskettiin vain nk. viileä versio, mikä tarkoittaa eristettyä rakennusta, jossa on koko seinän korkeudella verhoseinää.


Kuva 7. Naulalevyristikkorakenne

Liimapuinen kolminivelkehärakenne edustaa pihaton rakennustekniikkaa, joka on vallannut jalansijaa Suomessa viime vuosien aikana. Vesikaton toisiokannattajat ovat sahatavaraa. Vesikatteena on profiilipelti, jonka alle on kiinnitetty $5 \mathrm{~cm}$ paksuinen foliopintainen mineraalivilla. Sen tehtävänä on talvella estää kondenssi-ilmiötä pellin sisäpinnassa sekä kesällä antaa lämpösäteilysuojaa auringon lämmittävää vaikutusta vastaan. Seinät ovat yksikertaisia lautaseiniä ja niiden yläosat ovat verhoseinää. Tästä mallista laskettiin vain kylmäpihattoversio.


Kuva 8. Liimapuu-kolminivelkehärakenne

Vertaillut runkojärjestelmät oletettiin rakennettavaksi hyvin kantavalle maapohjalle. Sen lisäksi laskettiin vertailuluvut teräspaalutukselle $5 \mathrm{~m}$ syvyyteen ja betonipaalutukselle $10 \mathrm{~m}$ syvyyteen. Kaikki pihattojen lattiaratkaisut laskettiin betonisena avokouruna, mutta lisäksi tarkasteltiin matalan alaraappakanaalin sekä syvenevän valutuskanaalin versioina.

\section{Menetelmät}

Rakennusten kokonaismateriaalivirrat laskettiin taulukkolaskentaohjelmaan pohjautuvalla työkalulla. Kaiken pohjana oli lista rakennusmateriaaleista, joille kullekin oli määritelty MI-arvot. Mukaan otettiin eri lähteistä myös hiilidioksidikertoimet, raaka-ainemenekki, tuotannossa syntyneen jätteen määrä sekä käytetty energia jaettuna uusiutuvaan ja uusiutumattomaan energiaan. Pääasiallisena lähteenä rakennusosien materiaalimäärissä oli Rakennustietosäätiön ja Rakennustieto Oy:n Rakennusten ja rakennusosien ympäristöselosteet (Saari 2001). Lähteen mittojen mukaan materiaaleille laskettiin tiheyden kautta massat. Massalla kerrottiin kunkin materiaalin päästökertoimet, jotka summaamalla tuloksena oli rakennusosayksikköä kohden ilmoitetut ympäristövaikutukset. Suurin osa rakennusosista oli helpointa 
laskea neliömetreinä. MIPS-termin mukaisesti materiaalikulutus lasketaan jotain yksikköä kohden. Pihaton tapauksessa materiaali-intensiteetti voidaan laskea esimerkiksi rakennettua neliömetriä tai kuutiometriä kohden. Luvut voitaisiin myös laskea vaikkapa tuotettuja maitolitroja kohden. Tarkastelun tuloksissa päädyttiin kuitenkin osoittamaan intensiteetti parsipaikkaa kohden, koska se kuvastaa yhden lehmän aiheuttamaa rakentamisen- ja materiaalivirtojen määrää.

\section{Tulokset}

Tuloksissa keskityttiin analysoimaan pääasiassa materiaalien ja energian kulutusta, jätteiden määrää ja hiilidioksidipäästöjä. Ilman ja veden kulutus jätettiin pois, koska niiden rooli on vaikeaselkoinen. Luonnonvaroja tarvitaan tarkastelluissa 9 runkovaihtoehdossa pienimmillään noin 30 tonnia ja enimmillään 37,5 tonnia parsipaikkaa kohden. Ekotehokas rakentamistapa käyttää mahdollisimman paljon uusiutuvia luonnonvaroja, mikä suosii puuraaka-aineeseen perustuvia ratkaisuja. Samasta syystä betoniratkaisut ovat ekotehokkuuden kannalta epäsuotuisampia.



Kuva 9. Pihattovaihtoehtojen materiaali-intensiteetti kiloina parsipaikkaa kohden

Materiaali-intensiteetin näkökulmasta kaksi parasta vaihtoehtoa ovat harva puupilari-palkkirunko ja teräksinen kolminivelkehä. Ensin mainitussa puuta on käytetty rakenteellisesti säästeliäästi dimensiot optimoiden ja viime mainitussa korostuu teräksen materiaalinen keveys suhteessa lujuuteen, jolloin tehokkaalla materiaali-intensiteetillä voidaan kattaa laajojakin lattiapinta-aloja. Materiaali-intensiteetti ei tässä tarkoita samaa kuin rakennuksen paino, koska kiertokulkuun materiaalin synty- tai kaivannaispaikalta valmiiksi asennetuksi rakennusosaksi liittyy sivuvirtoja, jotka eivät päädy osaksi itse rakennusta.

Energian kokonaistarve tarkastelluissa 9 runkovaihtoehdossa on pienimmillään 7700 megaloujea ja enimmillään liki 14000 megajoulea parsipaikkaa kohden. Ekotehokas rakentamistapa käyttää mahdollisimman paljon uusiutuvaa energiaa, mikä suosii materiaali-intensiteetin tapaan puuraakaaineeseen perustuvia ratkaisuja. Aivan samasta syystä betoniratkaisut ovat energiatehokkuuden kannalta epäsuotuisampia. Kaikki puurunkovaihtoehdot ovat uusiutuvan energian näkökulmasta optimaalisia. Kolme parasta runkovaihtoehtoa energioiden kannalta ovat teräksinen kolminivelkehä, liimapuinen kolminivelkehä sekä harva puupilari-palkkirunko. Puupilarirunkojen lämpöeristäminen laski rakentamisvaiheen energiatehokkuutta epäedullisemmaksi. 




Kuva 10. Pihattovaihtoehtojen energia-intensiteetti kiloina parsipaikkaa kohden

Jätemäärä kuvaa materiaalien jalostusketjussa niiden synty- tai kaivannaispaikalta valmiiksi asennetuksi rakennusosaksi syntyviä jätemassoja, jotka jäävät rasittamaan ympäristöä ja jotka on loppusijoitettava jollain tavalla. Puutuotteiden jätemassoja voidaan polttaa energiaksi, jolloin ne voidaan vielä hyödyntää tehokkaasti. Kiviainekset voidaan käyttää maanrakennusaineena, mutta erilaiset kemianteollisuuden komponentit saattavat olla haitallisia ja hankalia käsitellä. Ekotehokkuuden kannalta betonirakennukset ovat epäedullisempia kuin liimapuunivelkehäratkaisu tai eristämätön puupilari-palkkiratkaisu.



Kuva 11.. Pihattovaihtoehtojen jäteintensiteetti kiloina parsipaikkaa kohden

Hiilidioksidipäästöt kuvaavat rakennusmateriaalien tuotantovaiheessa ja rakennusvaiheessa syntyviä päästöjä. Osa päästöistä johtuu eri työvaiheissa tarvittavan energian tuotannosta, jolloin ratkaisevaa on, millä energiamuodolla tuotantovaihe on suoritettu. Päästötarkastelussa puu- ja betoniratkaisut käyttäytyvät samalla trendillä kuin materiaali-intensiteetin, energian ja jätteiden muodostuksen tapauksissa: puuratkaisut ovat ympäristöystävällisempiä kuin betoniratkaisut. Kiintoisaa on se, että materiaali- ja energiaintensiteetissä hyvin pärjännyt teräsrunkomalli muuttui hiilidioksidipäästöissä epäedullisemmaksi. 


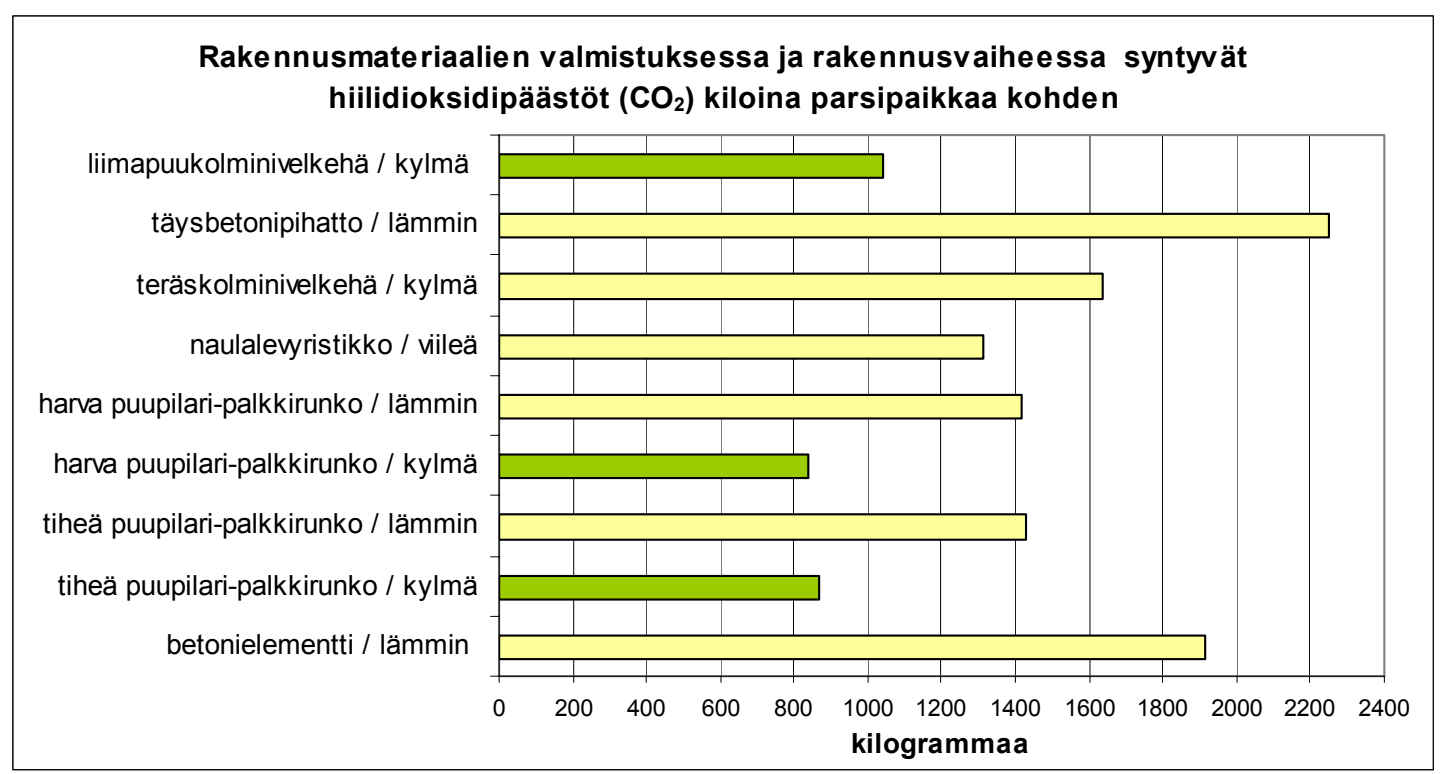

Kuva 12. Pihattovaihtoehtojen hiilidioksidipäästöt kiloina parsipaikkaa kohden

\section{Loppupäätelmät}



Kuva 13. Ympäristöä vähiten rasittavien pihattorakenteiden leikkauskuvat sekä valokuvaesimerkit vasemmalla Suomalaisesta ja oikealla Virolaisesta kylmäpihatosta.

Tarkasteltujen neljän muuttujan materiaali-intensiteetti, energian kulutus, jätteiden määrä ja CO2-päästöt yhteisvaikutuksena voidaan todeta, että vähiten ympäristöä rasittavat rakennuskonseptit ovat liimapuinen kolminivelkehä ja puupilari-palkkirunko ilman eristeitä eli kylmäpihattona. Menetelmänä MIPS keskittyy yleensä vain uudisrakennusvaiheen prosesseihin, ja korjaustoiminta ja purkuvaihe jää huomiotta. Kun kylmäpihattojen rakennus- ja liitostekniikka mietitään jo uudisrakennusvaiheessa modulaariseksi, päästään helposti korjattaviin ja purettaviin rakennustyyppeihin, joiden osia voidaan purkuvaiheenkin jälkeen valikoidusti käyttää seuraavissa uudisrakennuksissa. Näin ekotehokkuutta voidaan kasvattaa entisestään.

\section{Lähdekirjallisuus}

Nässén, J. Holmberg, J. Wadesskog, A. Nyman, M. 2007 Direct and indirect energy use and carbon emissions in the production phase of buildings: An input-output analysis, Energy Volume 32 Issue 9, September 2007.01.002

Junnila, S; Saari, A (1997): Rakennusosien aiheuttamien ympäristökuormien laskenta (Material and Energy Flow Estimation for Building Elements in the context of LCA). Helsinki University of Technology, Faculty of Civil and Environmental Engineering. Construction Economics and Management. Report 150. Espoo 1997. 90 p. Junnila,S., Saari, A. Asuinkerrostalon rakennusteknisten rakennusosien elinkaaren ympäristökuormat. TKK Rakentamistalous 1998 / 167. $101 \mathrm{~s}$.

Schmidt-Bleek, F., 2002. Luonnon uusi laskuoppi. 311 s. 